\title{
Implementasi Model Teaching Game for Understanding terhadap Keterampilan Bermain dalam Strike and Fielding Games
}

\author{
Implementation of Teaching Game for Understanding Model on Play Skills \\ in the Strike and Fielding Games
}

\author{
Dedi Supriadi \\ STKIP Pasundan, Cimahi, Jawa Barat, Indonesia \\ dedis25121960@gmail.com
}

\begin{abstract}
Abstrak
Tujuan penelitian ini adalah untuk mengetahui implementasi pembelajaran Teaching Game for Understanding (TGfU) terhadap keterampilan strike and fielding games. Metode penelitian yang digunakan adalah eksperimen dengan pretes and posttest control group desain. Populasi penelitian ini adalah mahasiswa STKIP Pasundan tingkat 3 semester 5 tahun akademik 2018/2019, dengan sampel sebanyak 120 orang. Teknik pengambilan sampel menggunakan cluster random sampling. Instrument yang digunakan untuk mengukur keterampilan bermain permainan bola kecil adalah Game Performance Assessment Instrument (GPAI). Penelitian dilakukan selama 6 minggu sebanyak 12 kali dengan 2 jam setiap pertemuan. Materi penelitian ini adalah kasti, kippers dan bola bakar. Analisis data menggunakan paired samplest-test.Hasil penelitian menunjukan adanya pengaruh yang signifikan dari implementasi model Teaching Game for Understanding terhadap keterampilan bermain dalam strike and fielding games.

Kata kunci: keterampilan bermain, model pembelajaran, TGfU, strike and fielding games
\end{abstract}

\begin{abstract}
This study aimed to recognize the implementation of Teaching Game for Understanding (TGfU) modelon the strike and fielding games. The method used in this research was an experimental research method with pretest and posttest control group design. The population was the undergraduate students of STKIP Pasundan which was only involved 120 students as a sample. In determining the sample, the research applied cluster random sampling. For the instrumentation, the researcher used Game Performance Assessment Instrument (GPAI) to test the students'strike and fielding games skills. the research was administered as many as 12 times with two hours of meeting in six weeks. The games tested were kasti, kippers, and bola bakar. The data gathered then analyzed by using paired samples t-test. The result showed that there was significant effect of the implementation of Teaching Game for Understanding method on the students'strike and fielding games skills.
\end{abstract}

Keywords: teaching model, TGfU, strike and fielding games, play skill

\section{PENDAHULUAN}

Keterampilan bermain penting dimiliki oleh olahragawan. Dalam olahraga permainan seperti bola voli tidak hanya teknik permainan saja yang penting tapi keterampilan bermain sangatlah dibutuhkan. Dengan bantuan permainan sederhana, siswa dan atlet harus didorong untuk mengembangkan pemahaman permainan dan kesadaran taktis dengan merefleksikan permainan dalam proses permanen dalam diskusi kelompok.
Guru dan pelatih mengajukan pertanyaan tentang "apa," "di mana," dan "mengapa," dan bukan hanya "bagaimana." Dengan cara ini, interaksi lisan dan tubuh dalam permainan sangat terkait erat. Dengan demikian, konsep tersebut telah berubah selama beberapa dekade terakhir ke pendekatan yang lebih berpusat pada siswa, berbasis masalah dan jauh dari pendekatan yang berpusat pada guru (Tan, Chow, \& Davids, 2012).

Manfaat pemebelajaran TGFU murid 
mengalami peningkatan dalam pengambilan keputusan, pelaksanaan teknis, perlindungan, dukungan, kinerja permainan, keterlibatan permainan, kesenangan, kompetensi yang dirasakan, dan niat untuk aktif secara fisik setelah implementasi unit TGfU. Para siswa dan guru merasakan peningkatan dalam semua variabel yang dianalisis sebagai konsekuensi dari intervensi (MoralesBelando, Calderón, \& Arias-Estero, 2018).Selain itu pendekatan permainan menunjukkan hasil bahwa pendekatan taktis permainan dapat meningkatkan perilaku metakognitif di kelas pendidikan jasmani di sekolah dasar (Chatzipanteli, Digelidis, Karatzoglidis, \& Dean, 2016). TGFU berpotensi sebagai model pedagogis yang digunakan untuk mencapai pengembangan keterampilan permainan, baik pengembangan taktis dan motorik, standar konten kurikulum(Stolz \& Pill, 2014). Penelitian menunjukkan bahwa strategi pengajaran yang berfokus pada permainan muncul untuk mempromosikan iklim motivasi yang berorientasi pada penguasaan dan, memiliki potensi untuk meningkatkan motivasi siswa dalam pembelajaran penjas (Gray, Sproule, \& Morgan, 2009).

Keterampilan bermain dalam pembelajaran permainan jauh lebih komplek dari pada keterampilan tertutup maupun terbuka. Siswa tidak hanya dituntut mampu melakukan dan mengunakan keterampilan tersebut, tetapi juga harus mengkombinasikan keterampilan dengan orang lain pada kondisi dan situasi yang bisa berubah-ubah, sehingga harus dibutuhkan strategi dan taktik dalam permainan (Susworo, 2006). Kondisi ini kadang membingungkan mahasiswa.
Mahasiswa yang memilki tekinik yang bagus belum tentu dapat bermain dengan berbagai situasi. Kebutuhan ini yang membuat pembelajaran dengan pendekatan taktis sangat efektif. Mahasiswa dibiasakan untuk senantiasa berada dalam permainan yang komplek dan tidak hanya mempelajari satu teknik saja. Model TGfU didahului dengan penekanan pada teknik apa yang digunakan dan kapan dan di mana untuk menggunakannya. Siswa harus didorong untuk melaksanakan strategi atau prinsip main yang menyeluruh seperti penggunaan kedalaman dalam permainan net seperti badminton. Masalah taktis seperti mengatur serangan dengan menciptakan ruang di sisi lawan gawang dapat diatasi dengan efektif atau keterampilan bergerak tanpa bola (Ward \& Griggs, 2011).

Permasalahan dilapangan dalam pedagogi tradisional, metode pengajaran berbasis kinerja menerapkan latihan keterampilan dan praktek teknik masih mendominasi pendidikan jasmani (Stolz \& Pill, 2014). Keterampilan teknik yang mendominasi seringkali mengabaikan keterampilan dalam bermain khususnya bermain bersama tim. Untuk melakukan permainan bola kecil tidak hanya kemampuan teknik yang dibutuhkan akan tetapi kemampuan bermain. Untuk itu perlu dilakukan pembelajaran yang mampu mengakomodir keterampilan teknik dan keterampilan taktis dalam permainan. Sehingga penelitian ini menggunakan model Teaching Games For Understanding (TGfU). Model TGfU berpotensi: (1) untuk memfasilitasi pengembangan keterampilan teknis dan pengetahuan taktis; (2) memberdayakan anak-anak untuk belajar 
sendiri dan bertanggung jawab; (3) untuk menilai transfer taktis di seluruh permainan; dan (4) untuk meningkatkan kesenangan dan kesenangan dalam bermain game(Wang \& Ha, 2012). Dengan demikian diras perlu untuk meneliti dampak yang diberikan dari model TGFU terhadap keterampilan bermain dalam permainan bola kecil.

\section{METODE PENELITIAN}

Penelitian ini menggunakan metode eksperimen, dengan pretes and posttest group desain (Fraenkel, Wallen, \& Hyun, 2012). Populasi penelitian ini adalah mahasiswa STKIP Pasundan tingkat 3 tahun akademik 2018/2019. Sampel penlitian sebnyak 127 orang mahasiswa. Teknik pengambilan sampel menggunakan cluster random sampling. Instrument yang digunakan untuk mengambil data adalah "Games Performance assessment Instrument (GPAI)" (Memmert \& Harvey, 2010), yaitu sebagai berikut:

Tabel 1. Komponen Permainan yang Diamati di GPAI (Definisi Umum)

\begin{tabular}{ll}
\hline \multicolumn{1}{c}{ Komponen Permainan } & \multicolumn{1}{c}{ Deskripsi } \\
\hline decision making & $\begin{array}{l}\text { Membuat keputusan yang tepat tentang apa yang harus dilakukan dengan bola } \\
\text { selama pertandingan }\end{array}$ \\
\hline Skill execution & Eksekusi Efisien keterampilan yang dipilih \\
\hline Adjust & Gerakan pemain, baik secara ofensif, seperti yang dituntut oleh alur permainan \\
\hline Cover (Bertahan) & $\begin{array}{l}\text { Memberikan perlindungan yang tepat, bantuan, mendukungkepada pemain } \\
\text { yang sedang memegang bola }\end{array}$ \\
\hline Support & $\begin{array}{l}\text { Memberikan dukungan yang tepat untuk rekan satu tim dengan bola dengan } \\
\text { berada dalam posisi untuk menerima umpan }\end{array}$ \\
\hline Guard/Mark & $\begin{array}{l}\text { Menjaga / menandai lawan dengan tepat baik yang memegang bola ataupun } \\
\text { tidak }\end{array}$ \\
\hline Base & Kembali ke posisi semula sesuai dengan tugas masing-masing \\
\hline
\end{tabular}

Tabel 2. Definisi Prilaku pada Permainan Strike and Fielding Games

\begin{tabular}{ccl}
\hline Nilai & \multicolumn{1}{c}{ Rating } & \multicolumn{1}{c}{ Definisi } \\
\hline 5 & Kinerja yang sangat efektif & $\begin{array}{l}\text { Selalu berusaha untuk berbagi; berkomunikasi mendukung kepada orang } \\
\text { dengan atau tanpa bola pada tim. Mampu menempatakan bola dengan } \\
\text { tepat pada saat menyerang dan mampu mendukung teman satu team pada } \\
\text { saat mencoba mematikan lawan. }\end{array}$ \\
\hline 4 & Kinerja yang efektif & $\begin{array}{l}\text { Sebagian besar waktu digunakan untuk berbagi : berkomunikasi } \\
\text { mendukung kepada orang dengan atau tanpa bola pada tim. Mampu } \\
\text { menempatakan bola dengan tepat pada saat menyerang dan mampu } \\
\text { mendukung teman satu team pada saat mencoba mematikan lawan. }\end{array}$ \\
\hline 3 & Cukup efektif & $\begin{array}{l}\text { Mencoba berkomunikasi dengan tim pada saat bertahan atupun } \\
\text { menyerang. Mencoba memukul dengan baik dan mencoba bertahan } \\
\text { seperlunya. }\end{array}$ \\
\hline 2 & Kinerja rendah & $\begin{array}{l}\text { Jarang berkomunikasi dengan rekan satu tim baik pada saat menyerang } \\
\text { atupun bertahan. Cenderung asal-asalan ketika melakukan berbagai } \\
\text { teknik baik memukul pada saat menyerang ataupun bertahan. }\end{array}$ \\
\hline 1 & Kinerja sangat rendah & $\begin{array}{l}\text { Tidak pernah berkomunikasidenganteman satu tim. Tidak memperdulikan } \\
\text { keadaan team baik saat menjadi pemukul ataupun menjadi regu penjaga. }\end{array}$ \\
\hline & &
\end{tabular}


Tabel 3. Penilaian GPAI

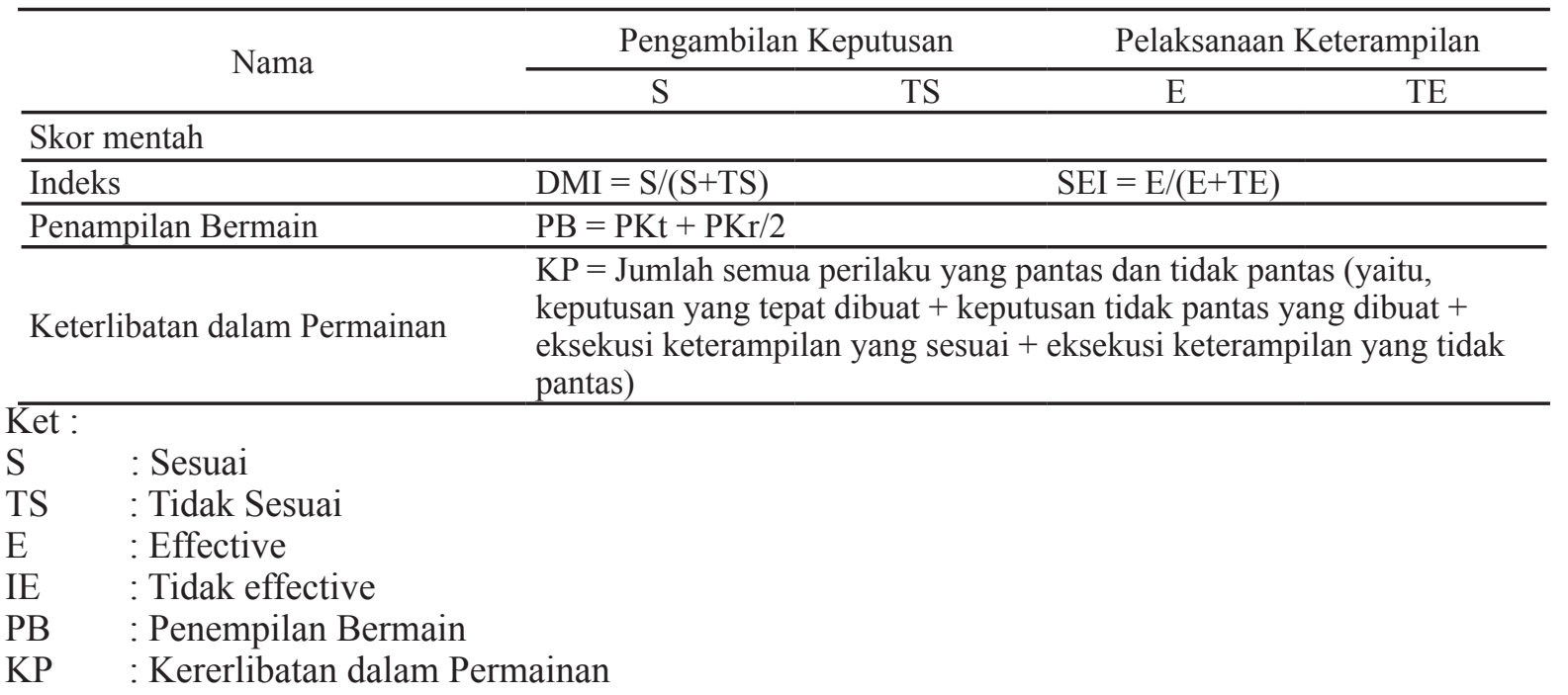

Penelitian ini selain menggunakan instrument GPAI, dalam pengambilan datanya dibantu dengan kamera untuk mengambil video pada saat sample sedang bermain. Kamera ditempatkan pada empat sudut, sehingga dapat terlihat jelas performa mahasiswanya. Penelitian ini dilakukan selama 6 minggu dengan pertemuan sebanyak 12 kali dengan 2 jam setiap pertemuan. Materi penelitian ini adalah kasti kippers dan bola bakar. Analisis data menggunakan paired samples $t$-test.

\section{HASIL DAN PEMBAHASAN}

\subsection{Hasil}

Data yang diperoleh dari hasil GPAI selanjutnya diolah menggunakan SPSS 21 dengan hasil sebagai berikut:

Tabel 4. Paired Samples Test

\begin{tabular}{|c|c|c|c|c|c|c|c|c|c|}
\hline & & \multicolumn{5}{|c|}{ Paired Differences } & \multirow{3}{*}{$\mathrm{t}$} & \multirow{3}{*}{ df } & \multirow{3}{*}{$\begin{array}{c}\text { Sig. } \\
\text { (2-tailed) }\end{array}$} \\
\hline & & \multirow[t]{2}{*}{ Mean } & \multirow[t]{2}{*}{$\begin{array}{c}\text { Std. } \\
\text { Deviation }\end{array}$} & \multirow[t]{2}{*}{$\begin{array}{l}\text { Std. Error } \\
\text { Mean }\end{array}$} & \multicolumn{2}{|c|}{$\begin{array}{l}95 \% \text { Confidence } \\
\text { Interval of the } \\
\text { Difference }\end{array}$} & & & \\
\hline & & & & & Lower & Upper & & & \\
\hline $\begin{array}{l}\text { Pair } \\
1\end{array}$ & $\begin{array}{l}\text { TGFU } \\
\text { Eksperiment }\end{array}$ & 4.501 & 3.072 & .801 & 3.323 & 4.501 & 8.859 & 5 & .000 \\
\hline
\end{tabular}

Berdasarkan tabel di atas diperoleh hasil signifikansi sebesar $0,000<0,05$ hal ini berarti terdapat pengaruh yang signifikan dari Teaching Game for Understanding terhadap keterampilan bermain dalam, strike and fielding games mahasiswa.

\subsection{Pembahasan}

Hasil penelitian menunjukan adanya pengaruh yang signifikan dari penerapan TGfU terhadap keterampilan bermain dalam permainan bola kecil. Hal ini dapat terjadi karena, TGfU memberikan keleluasaan bagi mahasiswa untuk bermain. TGfU telah menekankan tidak hanya pentingnya taktik tetapi juga cara di mana taktik dipelajari. Dari perspektif pedagogis, kita tahu bahwa siswa yang terlibat di tingkat yang lebih tinggi belajar lebih banyak (Butler \& Linda L. Griffin, 2010). Mahasiswa yang diberikan kesemapatan lebih banyak belajar maka akan semakin mampu menguasai taktik dan teknik dalam suatu permainan khususnya dalam penelitian ini permainan bola kecil. 
siswa dengan pendekatan TGfU dalam berbagai kegiatan dari dua versus dua atau tiga berbanding tiga, para siswa memiliki kesempatan untuk membuat keputusan tentang apa yang harus dilakukan dengan bola (Ray \& Michael, 2011). Dengan demikian mahasiswa akan memiliki banyak kesempatan untuk melakukan dan mengetahui cara yang tepat dalam mengambil keputusan. Dalam permainan, siswa mengamati pemain lain, berpikir tentang taktik, membuat keputusan tentang penggunaan keterampilan olahraga, dan menyelesaikan masalah taktis yang muncul selama pertandingan dengan demikian, TGfU adalah cara yang baik untuk mendorong pemikiran mendalam di kalangan siswa.

Tujuan pendekatan berbasis teknik adalah untuk mempelajari pelaksanaan teknis sebelum bermain game, pendekatan TGfU menunjukkan bahwa pemahaman permainan harus diperkenalkan melalui permainan yang dimodifikasi sebelum eksekusi teknis. Ini berarti bahwa untuk berpartisipasi dengan kesadaran, siswa harus secara eksplisit tahu kapan, di mana, dan mengapa menggunakan teknik dalam permainan dan bukan hanya eksekusi teknis belaka (Morales-Belando et al., 2018). Kemudian Pengajaran dengan pendekatan bermaindengan permainan yang dimodifikasi bertujuan untuk memberikan makna serta relevansinya dengan permainan adalah untuk mengembangkan keterampilan dan pada saat yang sama mengembangkan pemahaman (Light, 2012). Selanjutnya (Ray \& Michael, 2011) yang melaporkan bahwa pendekatan yang berpusat pada permainan dapat membantu siswa untuk memahami, menerapkan, menganalisis dan mengevaluasi tindakan mereka.

Selain itu Kunci keberhasilan TGfU adalah teknik bertanya dan relevansinya dengan siswa tentang pengenalan aturan dan teknik. Fokusnya adalah pada siswa dan pemecahan masalah. Pendekatan pengajaran ini sangat efektif menggunakan pembelajaran aktif di mana siswa belajar melalui permainan (Webb, Pearson, \& Forrest, 2006). Dalam permainan, siswa mengamati pemain lain, berpikir tentang taktik, membuat keputusan tentang penggunaan keterampilan olahraga, dan menyelesaikan masalah taktis yang muncul selama pertandingan. Dengan demikian, TGfU adalah cara yang baik untuk mendorong pemikiran mendalam di kalangan peserta didik (Wang \& Ha, 2013). Ini menandakan bahwa pendekatan pembelajaran melalui permainan dalam model TGfU mampu meningkatkan keterampilan mahasiswa khsusunya dalam strike and fielding games.

\section{SIMPULAN}

Model TGFU merupakan model berbasis permainan. Dalam penelitian ini permainan diberikan melalui berbagai permainan bola kecil sperti kasti, kippers dan bola bakar. Berdasarkan analisis dan pengolahan data yang telah dilakukan maka kesimpulan dalam penelitian ini adalah terdapat pengaruh yang signifikan dari penerapan model Teaching Games for Understanding (TGfU) terhadap keterampilan bermain permainan bola kecil. 


\section{DAFTAR RUJUKAN}

Butler, J. I., \& Linda L. Griffin. (2010). More Teaching Games for Understanding. (Scott Wikgren, Ed.), Journal of Experimental Psychology: General. United States of America: Human Kinetics.

Chatzipanteli, A., Digelidis, N., Karatzoglidis, C., \& Dean, R. (2016). A tactical-game approach and enhancement of metacognitive behaviour in elementary school students. Physical Education and Sport Pedagogy, 21(2), 169-184. https://doi.org/10.1080/17408989.2014.931366

Fraenkel, J. R., Wallen, N. E., \& Hyun, H. H. (2012). How to Design and Evaluate Research in Education. The McGraw-Hill Companies. https://doi.org/10.1017/CBO9781107415324.004

Gray, S., Sproule, J., \& Morgan, K. (2009). Teaching team invasion games and motivational climate. European Physical Education Review, 15(1), 65-89. https://doi.org/10.1177/1356336X09105212

Light, R. (2012). Game sense: Pedagogy for performance, participation and enjoyment. Game Sense: Pedagogy for Performance, Participation and Enjoyment. https://doi.org/10.4324/9780203114643

Memmert, D., \& Harvey, S. (2010). Identification of non-specific tactical tasks in invasion games. Physical Education and Sport Pedagogy, 15(3), 287-305. https://doi.org/10.1080/17408980903273121

Morales-Belando, M. T., Calderón, A., \& Arias-Estero, J. L. (2018). Improvement in game performance and adherence after an aligned TGfU floorball unit in physical education. Physical Education and Sport Pedagogy, O(0), 1-15. https://doi.org/10.1080/17408989.2018.1530747

Ray, B., \& Michael, S. (2011). Developing Game Sense Through Tactical Learning: A Resource for Teachers and Coaches. New York, NY: Cambrige University Press.

Stolz, S., \& Pill, S. (2014). Teaching games and sport for understanding: Exploring and reconsidering its relevance in physical education. European Physical Education Review, 20(1), 36-71. https://doi. org/10.1177/1356336X13496001

Susworo, A. (2006). Acuan Pembelajaran Permainan Softball Model TGfU. Jurnal Pendidikan Jasmani Indonesia, 5(2). Retrieved from http://download.portalgaruda.org/article.php?article=52547\&val=468\&title=AC UAN PEMBELAJARAN PERMAINAN SOFTBALL MODEL TGfU

Tan, C. W. K., Chow, J. Y., \& Davids, K. (2012). “How does TGfU work?”: Examining the relationship between learning design in TGfU and a nonlinear pedagogy. Physical Education and Sport Pedagogy, 17(4), 331-348. https://doi.org/10.1080/17408989.2011.582486

Wang, L., \& Ha, A. S. (2012). Factors influencing pre-service teachers' perception of teaching games for understanding: A constructivist perspective. Sport, Education and Society, 17(2), 261-280. https://doi. org/10.1080/13573322.2011.607954

Wang, L., \& Ha, A. S. (2013). Three groups of teachers' views, learning experiences, and understandings of teaching games for understanding. Physical Education and Sport Pedagogy, 18(3), 336-350. https:// doi.org/10.1080/17408989.2012.666789

Ward, G., \& Griggs, G. (2011). Principles of Play: A proposed framework towards a holistic overview of games in primary physical education. Education 3-13, 39(5), 499-516. https://doi.org/10.1080/03004279.201 0.480945

Webb, P. I., Pearson, P. J., \& Forrest, G. (2006). Teaching Games for Understanding ( TGf U ) in primary and secondary physical education. ICHPER-SD International Conference for Health, Physical Education, Recreation, Sport and Dance, 1st Oceanic Congress, Wellington, New Zealand, (October), 1-4. https:// doi.org/10.1111/j.1551-2916.2008.02556.x 